Klinik araştırma/Clinical Research

\title{
Kars Devlet Hastanesi'nde ameliyat edilen batına penetran yaralanmalar
}

\section{Penetrating abdominal trauma cases operated at Kars State Hospital}

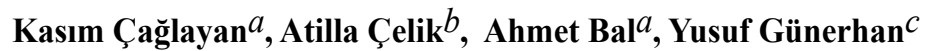 \\ a Bozok Üniversitesi, Tıp Fakültesi, Genel Cerrahi Anabilim Dal, Yozgat

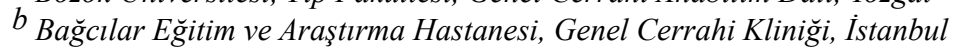 \\ ${ }^{c}$ Kafkas Üniversitesi, Tıp Fakültesi, Genel Cerrahi Anabilim Dalı, Kars
}

\begin{tabular}{|c|c|}
\hline MAK & GÍLERİ \\
\hline Makal & \\
\hline Geliş & $01 / 07 / 2010$ \\
\hline Kabul & 12 / 07 / 2010 \\
\hline *Yazış & \\
\hline Kasim & \\
\hline Bozok & tesi, Tıp Fakültesi, \\
\hline Genel & nabilim Dalı, \\
\hline $\begin{array}{l}\text { Adnan } \\
\text { e-posta }\end{array}$ & $\begin{array}{l}\text { s Bulvarı, No:190, Yozgat } \\
\text { glayan@hotmail.com }\end{array}$ \\
\hline
\end{tabular}

\section{ÖZET}

İkinci basamak sağlık kurumunda ameliyat edilen penetran karın yaralanmalarını epidemiyolojik olarak irdelemek. Eylül 2004 - Aralık 2008 tarihleri arasında Kars Devlet Hastanesine penatran karın yaralanması nedeni ile ameliyat edilen olgular retrospektif olarak incelendi. Hastalar yaş, cinsiyet, yaralanma nedeni; ateşli silah veya delici kesici alet, ameliyat bulguları ve komplikasyonlar açısından değerlendirildi. Penetran yaralanma nedeni ile ameliyat edilen 80 hastada yaş ortalaması:30,81+2 (8-83), kadın/erkek oranı:12/68(\%15/-\%85) idi. Hastalar yaş gruplarına göre incelendiğinde 15 yaş ve altı; 6 olgu $(\%$ 7,3) 16-64 yaş grubunda;71 olgu $(\% 86,6), 65$ yaş ve üstü; üç olgu $(\% 3,1)$ saptanmıştır. Yaralanma nedeni olarak $56(\% 70)$ olguda kesici delici alet, 24 (\%30) olguda ateşli silah yaralanması tespit edildi. Opere edilen olgulardan 16 hastada $(\% 20)$ negatif laparatomi yapılmıştır. Negatif laparatomi yapılan olgulardan 13'ü $(\% 23,5)$ kesici delici alet yaralanması, üç $(\% 12,5)$ olgu ise ateşli silah yaralanması nedeniyle ameliyat edilmişlerdi. Yaralanan organ sayısı olarak 21 olguda $(\% 32,8)$ tek organ yaralanması görülürken 43 olguda $(\% 67,2)$ birden fazla organ yaralanması görülmüştür. Organ yaralanması, en sık 18 olguda $(\% 28,1)$ İnce barsak, 12 olguda $(\% 18,8)$ kolon, 12 olguda $(\% 18,8)$ mide, 8 olguda $(\% 12,5)$ karaciğer, 8 olguda (\% 12,5) diafragma, 6 olguda $(\% 9,4)$ dalak, 3 olguda $(\% 4,7)$ böbrek, 2 olguda $(\%$ $3,1)$ pankreas yaralanması olarak tespit edilmiştir. Hastanede ortalama kalış süresi:5,9+2 (4-11) gündür. Dört olgu (\% 5) opere edildikten sonra hastaların yoğun bakım ihtiyaçları olması nedeniyle ileri bir merkeze sevk edilmiştir.Tarafımızdan tedavisi tamamlanan olguların 8 'inde (\% 10,5) komplikasyonlar görülmüştür. İkinci basamak sağlık kurumumuzda penetran karın yaralanmalarının daha çok genç erkeklerde ve delici-kesici alet ile oluştuğu, organ yaralanmasının çoğunlukla birden fazla olduğu, en sık yaralanan organın ise ince barsak olduğu görüldü. Penetran yaralanmaların büyük çoğunluğu ikinci basamak sağlık kurumlarında tedavi edilebilir. Ancak gerektiğinde ilk müdahalenin ardından ileri bir merkeze sevk edilmelidir.

J. Exp. Clin. Med., 2010; 27:54-57

\begin{abstract}
Epidemiological investigation of penetrating abdominal trauma cases operated at a secondary care setting. Penetrating abdominal trauma cases operated at Kars State Hospital between September 2004 and December 2008 were retrospectively investigated. Patients were reviewed with regard to age, gender, cause of injury (gunshot or stabbing), intraoperative findings, and complications. The mean age of 80 patients operated for penetrating trauma was $30.81 \pm 2$ y (range: $8-83$ y), with a female to male ratio of $12 / 68(15 \%$ females, $85 \%$ males). Age distribution of the cases was as follows: $\leq 15 \mathrm{y}, 6$ cases $(7.3 \%) ; 16-64 \mathrm{y}, 71$ cases $(86.6 \%) ; \geq 65 y, 3$ cases $(3.1 \%)$. Fifty-six cases $(70 \%)$ had stabbing injury and $24(70 \%)$ had gunshot injury. Sixteen of all laparotomies $(20 \%)$ did not reveal any internal organ lesion. Of these 16 laparotomies with negative findings, $13(23.5 \%)$ had been operated for stabbing injury and $3(12.5 \%)$ had been operated for gunshot injury. Twenty-one cases $(32.8 \%)$ had single organ injury; whereas, multiple organs were affected in 43 cases $(67.2 \%)$. Frequencies of organ injuries were as follows: small intestine, 18 cases $(28.1 \%)$; colon, 12 cases (18.8\%); stomach, 12 cases, (18.8\%); liver, 8 cases (18.8\%); diaphragm, 8 cases $(12.5 \%)$; spleen, 6 cases $(9.4 \%)$; kidney, 3 cases $(4.7 \%)$; and pancreas, 2 cases $(3.1 \%)$. The mean duration of hospitalization was 5.9 \pm 2 days (range: 4-11 days). After surgery, four cases
\end{abstract}


$(5 \%)$ needed intensive care unit; therefore, they were referred to a higher-level healthcare center. Among cases whom the treatment was completed in our institution, $8(10.5 \%)$ had complication. In our secondary care center, penetrating abdominal injuries mostly occurred in young males and stabbing injuries were more common. Most injuries involved multiple organs, with small intestine being the most frequently affected organ. Most penetrating injuries can be treated at secondary care centers. However, they should be referred to a higher-level institution after the initial intervention, when necessary.

J. Exp. Clin. Med., 2010; 27:54-57

Not: 10.th European Congress of Trauma and Emergency Surgery. 13-17 May, 2009 Antalya- Turkey'de Poster olarak sunulmuştur.

(C) 2009 OMÜ Tüm Hakları Saklıdır.

\section{Giriş}

Genel olarak travmaya bağlı ölümlerin \% 10’unu künt ve kesici delici karın yaralanmaları oluşturur. Ancak bu ölümlerin erken tanı, doğru ve hılı tedavi ile önlenebilir olması konunun önemini artırmaktadır (Emergen ve ark., 2002). Karına penetre kesici delici alet yaralanmalarinda, yaralayan alet ne olursa olsun hastanın tedavisinde temel esas; hızlı bir biçimde genel durum değerlendirilmesi, resüsitasyon ve yaralanmanın şekli ve yerine göre tedavi stratejisinin belirlenmesidir (Emergen ve ark., 2002). Tedavinin cerrahi olup olmayacağ tıp tarihi boyunca tartışılmış ve tedavinin şekli yıllardan beri değişikliklere uğramıştır. Eksplorasyon tanının gecikmesine bağlı mortalite ve morbiditeyi düzeltmesine rağmen, çoğu zaman gereksiz bir laparatomi yapılmasina neden olabilmektedir (Yıldırgan ve ark., 1996).

Son y1llara kadar karına penetre kesici delici alet yaralanmalarında omentum veya barsakların eviserasyonu, peritoneal lavajda kan gelmesi gibi bulgular karın eksplorasyonu için mutlak endikasyonlar olarak kabul görmüş olmasına karşın günümüzde bu kriterlerin eksplorasyon için net kriterler olmadığı görüşü yaygınlaşmıştır. Literatürde rutin eksploratris laparatomi şeklinde yaklaşımların yüksek oranda negatif veya non terapötik laparatomi ile sonuçlandığ 1 bildirilmektedir (Emergen ve ark., 2002; Schmelzer ve ark., 2008; Cothren ve ark., 2009).

$\mathrm{Bu}$ çalışmada amaç ülkemiz ikinci sağlık basamaği olan devlet hastanesinde batına penetre yaralanma nedeniyle opere edilen hastalarda sonuçlarımızı literatür eşliğinde incelemektir.

\section{Materyal - Metod}

Eylül 2004 - Aralık 2008 tarihleri arasında Kars Devlet Hastanesi'ne penetran karın yaralanması nedeni ile ameliyat edilen olgular retrospektif olarak incelendi. Hastalar yaş, cinsiyet, yaralanma nedeni; ateşli silah veya delici kesici alet, ameliyat bulguları ve komplikasyonlar açısından değerlendirildi.

\section{Bulgular}

Penetran yaralanma nedeni ile ameliyat edilen 80 hastada yaş ortalaması: $30,81(8-83)$ yıl, kadın/erkek oranı: 12/68 (\%15-\%85) idi. Hastalar yaş gruplarına göre incelendiğinde 15 yaş ve altı; 6 olgu $(\% 7,3) 16$ - 64 yaş grubunda; 71 olgu $(\% 86,6), 65$ yaş ve üstü; üç olgu $(\% 3,1)$ saptanmıştır. Yaralanma nedeni olarak 56 (\%70) olguda kesici delici alet, 24 (\%30) olguda ateşli silah yaralanması tespit edildi. Opere edilen olgulardan 16 hastada ( \%20)

Tablo-1:Hastalara ait demografik bilgiler.
\begin{tabular}{|c|c|c|c|c|c|c|}
\hline \multicolumn{2}{|c|}{ Yaralanma nedeni } & \multicolumn{2}{|c|}{ Cinsiyet } & \multicolumn{2}{c|}{ Laparatomi } & Komplikasyon \\
\hline \multicolumn{2}{|c|}{ Erkek } & Kadın & Pozitif & Negatif & \\
\hline $\begin{array}{c}\text { Kesici } \\
\text { alet }\end{array}$ & $\begin{array}{c}56 \\
(\% 70)\end{array}$ & $\begin{array}{c}50 \\
(\% 73)\end{array}$ & $\begin{array}{c}6 \\
(\% 50)\end{array}$ & $\begin{array}{c}43 \\
(\% 67)\end{array}$ & $\begin{array}{c}33 \\
(\% 81)\end{array}$ & $\begin{array}{c}4 \\
(\% 50)\end{array}$ \\
\hline $\begin{array}{c}\text { Ateşli } \\
\text { silah }\end{array}$ & $\begin{array}{c}24 \\
(\% 30)\end{array}$ & $\begin{array}{c}18 \\
(\% 27)\end{array}$ & $\begin{array}{c}6 \\
(\% 50)\end{array}$ & $\begin{array}{c}21 \\
(\% 33)\end{array}$ & $\begin{array}{c}3 \\
(\% 19)\end{array}$ & $\begin{array}{c}4 \\
(\% 50)\end{array}$ \\
\hline Toplam & 80 & 68 & 12 & 64 & 16 & 8 \\
\hline
\end{tabular}

negatif laparatomi yapılmıştır. Negatif laparatomi yap1lan olgulardan 13'ü $(\% 23,5)$ kesici delici alet yaralanmas1, üç $(\% 12,5)$ olgu ise ateşli silah yaralanması nedeniyle ameliyat edilmişlerdir (Tablo-1). Yaralanan organ sayıs1 olarak 21 olguda ( $\% 32,8)$ tek organ yaralanması görülürken 43 olguda $(\% 67,2)$ birden fazla organ yaralanmaS1 görülmüştür. Organ yaralanması, en s1k 18 olguda (\% $28,1)$ İnce barsak, 12 olguda $(\% 18,8)$ kolon, 12 olguda $(\% 18,8)$ mide, 8 olguda (\% 12,5) karaciğer, 8 olguda ( $\%$ 12,5) diafragma, 6 olguda $(\% 9,4)$ dalak, 3 olguda $(\% 4,7)$ böbrek, 2 olguda $(\% 3,1)$ pankreas yaralanması olarak tespit edilmiştir (Tablo-2). Hastanede ortalama kalış süresi: 5,9 (Alimoğlu, 2005; Kocakuşak ve ark., 2006; Inaba ve Demetriades, 2007; Kopelman ve ark., 2008; Cothren ve ark., 2009; Dozier ve ark., 2009; DuBase ve ark., 2009) gündür. Dört olgu (\% 5) opere edildikten sonra hastaların yoğun bakım ihtiyaçları olması nedeniyle ileri bir merkeze sevk edilmiştir.Bu olgular bir tanesi ateşli silah yaralanmas1 olup hastaya parsiyel ince barsak rezeksiyonu+ sağ hemikolektomi+ sağ psoas kas onarımı+lomber ven ligasyonu yapılmış olup hasta postoperatif takip amacıyla ileri bir merkeze sevk edilmiş olup hasta gittiği merkezde sadece medikal tedavi yapılmış ancak hasta postoperatif 13 . gün eksitus olmuştur. Kolon yaralanması olan bir başka olguya ise ince barsak rezeksiyonu+ sağ hemikolektomi+ saptırıcı ileostomi yapılmış olup hasta ileri bir merkeze sevk edilmiştir. Bu olgu gittiği merkezde takibi yapılmış ve postoperatif 8 . gün taburcu edilmiştir.Sevk edilen bir başka olguda ise pankreas yaralanması+kolon +mide per-

Tablo-2:Organ yaralanması ve dağılımı

\begin{tabular}{|l|c|c|}
\hline Yaralanan Organ & $\mathrm{N}$ & $\%$ \\
\hline İnce Bağırsak & 18 & $\% 28,1$ \\
\hline Kolon & 12 & $\% 18,8$ \\
\hline Mide & 12 & $\% 18,8$ \\
\hline Karaciğer & 8 & $\% 12,5$ \\
\hline Diafragma & 8 & $\% 12,5$ \\
\hline Dalak & 6 & $\% 9,4$ \\
\hline Böbrek & 3 & $\% 4,7$ \\
\hline Pankreas & 2 & $\% 3,1$ \\
\hline
\end{tabular}


forasyonu+ karaciğer yaralanması mevcut olup hastaya hasar kontrol cerrahisi yapılmış olup hasta entübe olarak sevk edilmiş olup hasta gittiği merkezde 24 saat sonra definitif operasyon geçirmiş olup hasta iyileşmiştir. Diğer olgu kesici delici alet yaralanması nedeniyle karaciğer yaralanması nedeniyle tarafımızdan hepatorafi yapılmış olup hasta takip amaciyla sevk edilmiş olup hasta gittiği merkezde sorunsuz taburcu edilmiştir. Tarafimızdan tedavisi tamamlanan olguların 8 'inde $(\%$ 10,5) komplikasyon görülmüştür. Bir olguda ileus, iki olguda atelektazi, beş olguda ise yara yeri infeksiyonu görülmüş olup tedavileri medikal olarak tamamlanmıştır. Tarafımızdan tedavi ve takibi yapılan olgularda mortalite görülmemiştir.

\section{Tartışma}

Batına penetre abdominal yaralanmalar acil serviste yaygın olarak görülür ve yaklaşımı travma cerrahları arasında farklılıklar gösterir. Laparatomi yapılan bu hastaların yaklaşık \% 11-40 negatif laparatomi ile sonuçlanır. Non terapötik laparatomilerin komplikasyonları ciddi olabilir ve mortalite \% 0-5, morbidite \%5-22 arasında değişebilmektedir (Alimoglu, 2005). Kesici delici alet yaralanmalarında mortalite ve morbidite oranları yaralanan organ sayısı ve önemi ile direk ilişkilidir.Tedavi seçimi ve optimal zamanlama bu oranların azaltılmasına katkıda bulunacaktır (Y1ldirgan ve ark., 1996).

Literatürde hastada şok, peritoneal irritasyon bulgularının olması, çoğunlukla müdahale edilmesi gereken bir patoloji göstergesi olarak kabul edilmektedir (Alimoglu, 2005; Kocakuşak ve ark., 2006). Eğer hastada hemodinamik stabilite varsa ve acil laparatomi endikasyonu yoksa konservatif tedavi veya laparatomi konusunda izlenecek yol tartışmalıdır. Bu durumda en önemli soru hangi tanısal yöntemlerin kullanılacağ1, hangi hastalara ne zaman laparatomi yapılacağıdır (Alimoglu, 2005). Örneğin bazı çalışmalarda (Dozier ve ark., 2009) ateşli silah yaralanmalarında agresif cerrahinin avantajlı olduğunu önerilirken, başka çalışmalarda ise (DuBose ve ark., 2007) yaptıkları çalışma sonunda ateşli silah yaralanmalarında izole solid organ yaralanması olan, hemodinamik stabilite ve peritonit olmayan olguların seri klinik muayenelerle \% 92 oranında başarılı bir şekilde nonoperatif olarak tedavi edildiğini ifade etmişlerdir. Aynı şekilde (Inaba ve Demetriades, 2007) yazılarında batına penetre yaralanmalarda hemodinamik stabilite ve periton sağlam olgularda seri klinik muayenelerle güvenle nonoperatif tedavi yapılabileceğini ifade etmişlerdir.Cerrahın kişisel özellikleri ve adli sorun çıkabileceği endişesi literatürde rastlanmayan sebeplerdendir.

Kesici delici alet yaralanmalarında, cerrahi sonrası çıkabilecek sorunların tolere edilmesinin, kişinin ameliyat edilmemesi ve takibi sonucu ortaya çıkabilecek sonuçlarının tolerasyonundan daha kolay olacağı düşüncesinin cerrahlar arasında yaygın olması, rutin eksplorasyon yönteminin tercihinde önemli bir etkendir (Kocakuşak ve ark., 2006). Bu amaçla non invaziv olarak; seri muayeneler ve klinik durum, ultrasonografi, bilgisayarlı tomografi, endoskopi ve manyetik rezonans, İnvaziv olarak da diagnostik peritoneal lavaj, anjiografi, intravenöz piyelogram, lokal yara eksplorasyonu,diagnostik laparaskopi yapılabilmektedir (Schmelzer ve ark., 2008; Alimoglu, 2005). Ancak bu yöntemlerin tek başına kullanılması tanı için her zaman yeterli bilgi vermeyebilir (Alimoglu, 2005). Başka bir yapılan çalışma sonunda Abdominal travmada algoritmde Bilgisayarlı Tomografi den sonra ve laparatomi arasında dönemde Diagnostik laparoskopinin kullanılması ile nonterapötik laparatominin \% 75 civarında önlenebileceğini ve bunun sonucunda maliyetin düşeceğini ifade etmişlerdir (Naveed ve ark., 2005).

Abdominal duvar yaralanmalarında tanısal değerlendirmede iki nokta önemlidir.Birinci olarak negatif laparatomi oranları minimize edilmeli,ikinci olarak da gecikmiş tanılarda morbidite ve mortaliteden kaçınmak için intraabdominal yaralanmalarda cerrahi sensitivitesi anlamlı olarak yüksek olmalıdır (Kopelman ve ark., 2008).

Ancak bütün bu diagnostik yöntemlere rağmen negatif laparatomi oranları. Kocakuşak ve ark., (2006) yılında yaptıkları 1996-1999 yılları arasına ait batına nafiz kesici delici alet yaralanmalarında negatif laparatomi oranlarını \% 18 olarak vermektedirler. Bizim çalışmamızda kesici delici alet yaralanmalarında negatif laparatomi oranı \% 23.5, ateşli silah yaralanmalarında ise \% 12.5 tir. Bizim oranlarımızı literatür ile karşılaştırdığımızda negatif laparatomi oranımızın yüksek olduğunu görmekteyiz. Bunun nedeni olarak da ülkemiz ikinci basamak sağlik kuruluşlarında batın travmalı olgularda diagnostik yöntem imkanlarının yetersiz olması ( Görüntüleme yöntemlerinin her zaman olmaması, kan replasmanı gerekliliğinde merkezdeki imkanların kısıtlı olması gibi), nonoperatif tedavi düşünülen hastaların takibi için yeterli ortamın olmaması olarak düşünmekteyiz. Bununla birlikte cerrahi sonrası çıkabilecek sorunların tolere edilmesinin, kişinin ameliyat edilmemesi ve takibi sonucu ortaya çıkabilecek sonuçlarının tolerasyonundan daha kolay olacağı düşüncesinin cerrahlar arasında yaygın olması, rutin eksplorasyon yönteminin tercihinde önemli bir etkendir.

Uludağ ve ark., (2009) yılında yaptıkları çalışmada batına penetre abdominal yaralanmalarda yaralanan organ olarak \%43.8 ince barsak, \%33.3 kolon ve \%15.5 olarak mide yaralanması görülürken diğer organ yaralanmaları daha az sıklıkla bulunmuştur. Bizim çalışmamızda yaralanan organ olarak en sik 18 olguda (\% 28.1) İnce barsak, 12 olguda (\%18.8) kolon, 12 olguda (\% 18.8) mide yaralanması görülmüş olup diğer intraabdominal organlarda yaralanma daha az sıklıkla görülmüştür.

Sonuç olarak batına penetran yaralanmalarda rutin eksplorasyon yapıldığında negatif laparatomi oranları yüksektir.Bu oranların daha düşük olması için diagnostik yöntemlerin kullanılması gerekmektedir.Cerrah bu olgularda çalıştığı merkezin imkanını iyi değerlendirmeli, gereksiz laparatomiden kaçınmalıdır.Ancak imkanların yetersiz olması durumunda hastanın lehine olacak ise tanı ve tedavi için diagnostik ve nonoperatif tedavi imkanlarının olduğu diğer merkezlere hastaya sevk etmelidir diye düşünmekteyiz. 


\section{KAYNAKLAR}

Ahmed, N., Whelan, J., Brownlee, J., Chari, V., Chung, R., 2005. The contribution of laparoscopy in evaluation of penetrating abdominal wounds. J. Am. Coll Surg. 201, 213-216.

Alimoglu, O., 2005. Laparoscopy in penetrating abdominal trauma. Eur. Surg. 37, 28-32.

Cothren, C.C., Moore, E.E., Warren, F.A., Kashuk, J.L., Biffl, W.L., Johnson, J.L., 2009. Local wound exploration remains a valuable triage tool fort he evaluation of anterior abdominal stab wounds. Am. J. Surg. 198, 223-226.

Dozier, K.C., Miranda, M.A., Kwan, R.O., Cureton, E.L., Sadjadi, J., Victorino, G.P., 2009. Despite the increasing use of nonoperative management of firearm trauma, shotgun injuries still require aggressive operative management J. Surg. Res. 156, 173-176

DuBose, J., Inaba, K., Teixeira, P.G.R., Pepe, A., Dunhamb, M.B., McKenney, M., 2007. Selective non-operative management of solid organ injury following abdominal gunshot wounds. Injury, Int. J. Care Injured. 38, 1084 - 1090.

Emergen, İ., Ekiz, F., Yücel, T., Akpınar, A., Gönüllü, D., Mecit, N., 2002. Karına penetre kesici delici alet yaralanmalarında selektif yaklaşım. Ulusal Travma Derg. 8, 209-214.

Inaba, K., Demetriades, D., 2007. The nonoperative management of penetrating abdominal trauma. Adv. Surg. 41, 51-62.

Kocakuşak, A.,Yücel, A.F., Arıkan, S., 2006. Karına nafiz delici-kesici alat yaralanmalarında rutin abdominal eksplorasyon yönteminin retrospektif analizi. Van Tip Derg.13, 90-96.

Kopelman, T.R., O’Neill, P.J., Macias, M.R., Cox, J.C., Matthews, M.R., 2008. The utility of diagnostic laparascopy in the evaluation of anterior abdominal stab wounds. Am. J. Surg. 196, 871-877.

Schmelzer, T.M., Mostafa, G., Gunfer, O.L., Norton, H.J., Sing, R.F.S., 2008. Evaluation of selective treatment of penetrating abdominal trauma. J. Surg. Education. 65, 340-345.

Uludăg, M., Yetkin, G., Çitgez, B., Yener, F., Akgün, İ., Çoban, A., 2009. Penetran ince barsak yaralanmalarında ek organ yaralanmasının morbidite ve mortalite üzerine etkisi. Ulusal Travma ve Acil Cerr. Derg. 15, 45-51.

Yıldırgan, M.İ., Polat, K.Y., Akçay, M.N., Salman, B., Polat, C., Atamanalp, S., Ören, D., 1996. Batına nafiz kesici-delici alet yaralanmaları. Ulusal Travma Derg. 1, 114-117. 